\title{
Analisis Kinerja Sistem Kelistrikan Akibat Penambahan Gedung Fakultas Keguruan Ilmu Pendidikan Universitas Lancang Kuning
}

\author{
Abrar Tanjung \\ Fakultas Teknik Program Studi Teknik Elektro, Universitas Lancang Kuning \\ Jl. Yos Sudarso Km 08 Rumbai \\ E-mail: abrar@unilak.ac.id
}

\begin{abstract}
ABSTRAK
Universitas Lancang Kuning merupakan suatu lembaga pendidikan yang memiliki beberapa fakultas yang mempunyai kegiatan admistrasi dan belajar mengajar, yang menggunakan peralatan listrik. Pemakaian beban listrik juga banyak dipakai dalam pemasangan lampu penerangan dan peralatan-peralatan listrik lainnya. Seperti penggunaan infokus dalam perkuliahan, penggunaan lampu penerangan setiap ruangan, penerangan jalan dan pemakaian peralatan kantor yang juga menggunakan energi listrik. Penambahan pembangunan Gedung Fakultas Keguruan dan Ilmu Pendidikan (FKIP) yang baru merupakan faktor dari akibat bertambahnya beban pemakaian energi listrik yang ada di Unilak. Berdasarkan hasil perhitungan rugi-rugi daya total sebesar 41.476 watt atau $41,476 \mathrm{~kW}$ dan tegangan terendah sebesar 236,60 volt di fakultas Hukum, total jatuh tegangan 278,75 volt dan ketidak seimbangan beban pada phasa $R$ sebesar 266,52 Amper, phasa S sebesar 186,3 Amper dan phasa R sebesar 133,4 Amper. Penambahan gedung Fakultas Keguruan dan Ilmu Pendidikan dengan memasang transformator daya sebesar $60 \mathrm{kVA}$
\end{abstract}

Kata kunci: Rugi-Rugi Daya, Energi Listrik, Jatuh Tegangan

\begin{abstract}
Lancang Kuning University is an educational institution that has a faculty that has administration and teaching and learning activities, the use of electrical equipment. The use of electrical load is also widely used in the installation of lighting and other electrical equipment. Such infocus use in lectures, the use of any room lighting, street lighting and the use of office equipment that also uses electrical energy. Addition Building of the Faculty of Teacher Training and Education (Guidance and Counseling) is a factor of the new ones due to the increasing burden of electrical energy consumption in Unilak. Based on the calculation of total power loss of 41476 watts or $41.476 \mathrm{~kW}$ and the lowest voltage of 236.60 volts at the faculty of Law, a total of 278.75 volts and the voltage drop across the load imbalance in phase $R$ of 266.52 Amper, $S$ phase by 186, 3 amperes and phase $R$ of 133.4 amperes. The addition of the building of the Faculty of Teacher Training and Education by installing a power transformer of $60 \mathrm{kVA}$.
\end{abstract}

Keywords: Power Losses, Electrical Energy, Voltage Drop.

UNITEX Vol 12 No.2 Juli-Desember 2019 p-ISSN 2089-3957 | e-ISSN 2580-2585 


\section{Pendahuluan}

Penggunaan energi listrik umumnya selalu menunjukkan gejala yang meningkat. Hal ini tidak bisa dipungkiri lagi, karena tenaga listrik merupakan bentuk energi yang sangat menguntungkan dan sangat membantu manusia dalam menyelenggarakan kehidupannya. Untuk menyalurkan kebutuhan tenaga listrik tersebut dari produsen listrik ke konsumen diperlukan suatu jaringan dan gardu distribusi. Berdasarkan Standar Perusahaan Listrik Negara (SPLN), sistem dapat dikatakan efektif bila drop tegangannya tidak melebihi $+5 \%$ dan $-10 \%$ dari tegangan nominal, rugi-rugi daya dan dari total daya yang disalurkan (3). Universitas Lancang Kuning merupakan lembaga pendidikan yang memiliki beberapa fakultas yang mempunyai kegiatan admistrasi dan belajar mengajar, yang menggunakan peralatan listrik. Pemakaian beban listrik juga banyak dipakai dalam pemasangan lampu penerangan dan peralatan-peralatan listrik lainnya. Seperti penggunaan infokus dalam perkuliahan, penggunaan lampu penerangan setiap ruangan, penerangan jalan dan pemakaian peralatan kantor yang juga menggunakan energi listrik.

Penambahan pembangunan Gedung Fakultas Keguruan dan Ilmu Pendidikan (FKIP) yang baru merupakan faktor dari akibat bertambahnya jumlah mahasiswa yang akan belajar dan kuliah di Universitas Lancang Kuning. Penambahan gedung tersebut juga akan mengakibatkan bertambahnya beban pemakaian energi listrik yang ada di Unilak. Hal ini dikarenakan terlaksananya kegiatan belajar mengajar yang akan menggunakan peralatan dan perlengkapan listrik. Dengan bertambahnya beban pemakaian energi listrik akan mempengaruhi besar kapasitas beban yang terpasang pada transformator dan mengakibatkan terjadinya beban lebih dan rugi daya serta drop tegangan di Universitas Lancang Kuning. Penelitian ini dilakukan untuk membahas tentang Kinerja kelistrikan di Universitas Lancang Kuning. Penambahan Gedung Fakultas Keguruan Ilmu Pendidikan (FKIP) merupakan faktor utama dalam penambahan energi atau daya listrik yang akan mempangaruhi kinerja sistem kelistrikan pada kondisi eksisting.

\section{Metode Penelitian}

Dalam rangka pengisian transformator, metoda oposisi yang diuraikan di dalam Standard IEC 60076-2 telah digunakan untuk merubah beban dan faktor daya. Sensor untuk mengukur getaran dan temperatur telah rangkai di transformator. transformator berbeda beroperasi pada masing-masing kondisi. Dalam rangka memverifikasi kemampuan model untuk mendeteksi kegagalan, suatu kelainan bentuk telah disebabkan oleh lilitan transformator (1)(5). Transformator atau trafo adalah jenis mesin listrik statis yang bekerja berdasarkan prinsip elektromagnetik. Secara umum trafo terdiri dari trafo daya, trafo tegangan dan trafo arus. Trafo daya adalah trafo yang bisaa digunakan di gardu induk maupun gardu distribusi. Sedangkan trafo tegangan dan trafo arus adalah trafo yang digunakan untuk pengukuran dan proteksi. Transformator atau trafo adalah jenis mesin listrik 
statis yang bekerja berdasarkan prinsip elektromagnetik. Secara umum trafo terdiri dari trafo daya, trafo tegangan dan trafo arus. Trafo daya adalah trafo yang bisaa digunakan di gardu induk maupun gardu distribusi. Sedangkan trafo tegangan dan trafo arus adalah trafo yang digunakan untuk pengukuran dan proteksi (2)(5)(6).

\section{Jenis-jenis Penghantar (Conductor)}

Kawat penghantar adalah suatu jenis alat yang berfungsi untuk memindahkan tenaga listrik dari suatu tempat ke tempat lain. Pemasangannya dapat berupa saluran udara (overhead lines) ataupun saluran bawah tanah (underground cable). Jenis-jenis penghantar yang biasa digunakan yaitu : tembaga dengan konduktivitas $100 \%$ (CU 100\%), tembaga dengan konduktivitas 97,5\% (CU 97,5\%) atau aluminium dengan konduktivitas $61 \%$ ( $\mathrm{Al} \mathrm{61 \% )} \mathrm{(2).}$

\section{Impedansi Saluran}

Untuk perhitungan jatuh tegangan, resistansi dan reaktansi kedua konduktor perlu diperhitungkan. Kombinasi antara resistansi dan reaktansi disebut dengan impedansi yang dinyatakan dalam satuan ohm.

Impedansi dapat dihitung dengan rumus :

$$
\mathrm{Z}=\mathrm{R}+\mathrm{jX}
$$

Maka :

$$
\mathrm{Z}=\sqrt{R^{2}+X^{2}} \quad \text { Ohm }
$$

Keterangan :

$$
\begin{aligned}
& \mathrm{Z}=\text { Impedansi saluran }(\mathrm{Ohm}) \\
& \mathrm{R}=\text { Tahanan saluran }(\mathrm{Ohm}) \\
& \mathrm{X}=\text { Reaktansi }(\mathrm{Ohm})
\end{aligned}
$$

\section{Tahanan}

Tiap konduktor memberi perlawanan atau tahanan terhadap mengalirnya arus listrik dan hal ini dinamakan resistensi. Resistensi atau tahanan dari suatu konduktor (kawat penghantar) diberikan oleh :

$$
R=\rho \frac{l}{A} \quad \text { Ohm }
$$

Keterangan :

$$
\begin{aligned}
\mathrm{R} & =\text { Resistansi (Ohm) } \\
\rho & =\text { Resistivitas (tahanan jenis penghantar) } \\
l & =\text { Panjang kawat (meter) }
\end{aligned}
$$

$\mathrm{A}=$ Luas penampang kawat $\left(\mathrm{mm}^{2}\right)$ 


\section{Rugi Daya pada Jaringan Distribusi}

Dalam penyediaan tenaga listrik, disyaratkan suatu level standar tertentu untuk menentukan kwalitas tegangan pelayanan. Secara umum ada 3 hal yang perlu dijaga kwalitasnya (2), yaitu :

1. Frekwensi $(50 \mathrm{~Hz})$

2. Tegangan $(+5 \%$ dan $-10 \%)$

3. Kehandalan

Rugi-rugi daya adalah besarnya daya yang hilang pada suatu jaringanan, yang besarnya sama dengan daya yang disalurkan dari sumber dikurangi besarnya daya yang diterima pada perlengkapan hubungan bagian utama. Besarnya rugi-rugi daya satu fasa dinyatakan dengan persamaan sebagai berikut :

$$
\Delta \mathrm{P}=\mathrm{I}^{2} \times \mathrm{R} \quad \text { (Watt) }
$$

Keterangan :

$$
\begin{aligned}
\Delta \mathrm{P} & =\text { Rugi daya pada jaringan (Watt) } \\
\mathrm{I} & =\text { Arus beban pada jaringan (Ampere) } \\
\mathrm{R} & =\text { Tahanan murni (Ohm) }
\end{aligned}
$$

Besar rugi-rugi daya pada jaringan tergantung pada besarnya tahanan dan arus beban pada jaringan tersebut. Untuk mengetahui besar rugi-rugi daya pada jaringan tiga fasa dapat dinyatakan dengan persamaan sebagai berikut :

$$
\Delta \mathrm{P}=3 \times \mathrm{I}^{2} \times \mathrm{R} \quad \text { ( Watt ) }
$$

\section{Jatuh Tegangan (Voltage Drop)}

Terjadinya jatuh tegangan pada saluran disuatu lokasi adalah disebabkan oleh bagian yang berbeda tegangan didalam suatu sistem daya tersebut dan juga dipengaruhi oleh resistansi, reaktansi, dan impedansi pada saluran. Jatuh tegangan pada saluran adalah selisih antara tegangan pada pangkal pengiriman dengan tegangan pada ujung penerimaan tenaga listrik. Berdasarkan rangkaian ekivalen saluran distribusi Gambar 1, jika ada arus yang mengalir melalui saluran distribusi maka akan terjadi penurunan tegangan sepanjang saluran (3).

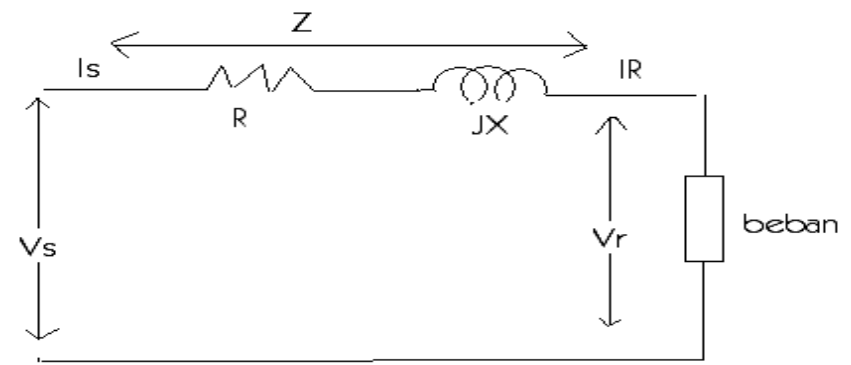

Gambar 1. Rangkaian ekivalen sistem distribusi 
Penurunan tegangan terdiri dari dua komponen :

a. $\quad I_{\mathrm{s}}$ yaitu rugi-rugi tegangan akibat tahanan saluran

b. I.X $X_{1}$ yaitu rugi-rugi tegangan akibat reaktansi induktif saluran

Besarnya rugi tegangan dapat dinyatakan sebagai berikut :

$$
\begin{aligned}
& \Delta V=I \cdot R \cdot \cos \varphi+I \cdot X \cdot \sin \varphi \\
& \Delta V=I x Z
\end{aligned}
$$

keterangan :

$\Delta V=$ Jatuh tegangan (Volt)

$I$ = Arus yang mengalir (Amper)

$R=$ Tahanan saluran $(\mathrm{Ohm})$

$X=$ Reaktansi $(\mathrm{Ohm})$

$\varphi=$ Sudut dari faktor daya beban

$Z=R+j X=$ impedansi saluran

Pada saluran arus bolak-balik besarnya jatuh tegangan tergantung dari impedansi saluran serta beban dan faktor daya. Untuk jarak yang dekat jatuh tegangan tidak begitu berarti. Perhitungan jatuh tegangan yang diperlukan tidak hanya untuk peralatan sistem saja namun juga untuk dapat menjamin tegangan terpasang yang dapat dipertahankan dalam batas-batas yang layak. Oleh karena itu perlu diketahui hubungan fasor antar tegangan dan arus serta reaktansi dan resistansi pada perhitungan yang akurat. Hubungan dengan diagram fasor antara tegangan pada sisi pengirim dari sebuah rangkaian dan jatuh tegangan pada ujung penerima ditunjukan pada Gambar 2.

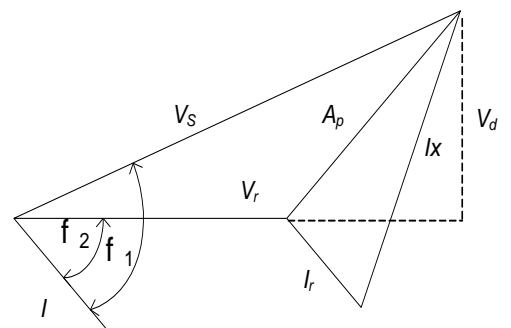

Gambar 2. Diagram Fasor hubungan tegangan dengan R dan X

Selanjutnya rumus jatuh tegangan dan rumus tegangan pada sisi pengiriman $\left(V_{s}\right)$ adalah sebagai berikut:

$$
\begin{aligned}
V_{s} & =V_{r}+I R x \cos \Phi+I X \sin \Phi \\
& =V_{r}+I x Z
\end{aligned}
$$

keterangan :

$$
\begin{array}{ll}
V_{s} & =\text { Tegangan kirim (Volt) } \\
V_{r} & =\text { Tegangan terima (Volt) } \\
I & =\text { Arus yang mengalir ( Amper }) \\
R & =\text { Tahanan saluran (Ohm) } \\
X & =\text { Reaktansi saluran (Ohm) } \\
\Phi & =\text { Sudut dari faktor daya beban }
\end{array}
$$




\section{Ketidakseimbangan Sistem}

Sistem tidak seimbang merupakan tegangan-tegangan dan arus-arus tidak seimbang pada keadaan kerja normal, hal ini berarti walaupun tegangan generator simetris tetapi arus tidak seimbang. Dalam hal ini suatu arus urutan akan menimbulkan jatuh tegangan dari semua urutan bersama-sama. Pada sistem satu garis bagian yang tidak seimbang yatitu antara titik $\mathrm{P}$ dan titik $\mathrm{Q}$ dapat ditunjukkan pada gambar 3 (6).

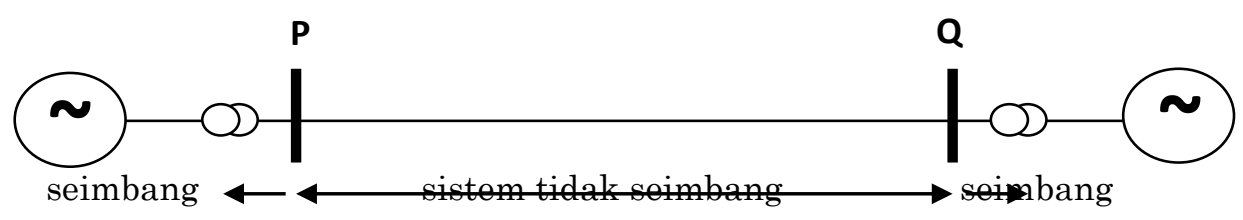

Gambar 3. Diagram satu garis sistem pada bagian yang tidak simetris

Tiga phasa seimbang jika :

a. besar arus atau tegangan sama besar

b. beda phasa sebesar $120^{\circ}$

Untuk sistem 3 phasa seimbang berlaku hubungan seperti persamaan 8 .

$\mathrm{I}_{\mathrm{n}}=\mathrm{I}_{\mathrm{R}}+\mathrm{IS}_{\mathrm{S}}+\mathrm{I}_{\mathrm{T}}=0$

Ketidakseimbangan arus atau tegangan dapat terjadi jika :

a. impedansi pada ketiga phasa tidak sama

b. beban pada ketiga phasa tidak sama

Bila beban dari phasa banyak seimbang merupakan beban dimana arus yang mengalir pada beban-beban simetris dan beban seperti ini biasanya diasumsikan dipasok oleh tegangan yang simetris. Dengan demikian analisanya dapat dilakukan pada basis per phasa saja. Dalam hal ini beban selalu diasumsikan seimbang setiap phasanya, sedangkan pada kenyataannya beban-beban tersebut tidak seimbang

\section{Hasil dan Pembahasan}

\section{Sistem Kelistrikan di Universitas Lancang Kuning}

Universitas Lancang Kuning merupakan lembaga pendidikan yang mempunyai beberapa gedung fakultas, gedung rektorat, gedung perpustakaan, Lembaga Penelitian dan Pengabdian Masyarakat (LPPM), Pusat komputer, Mesjid dan Asrama mahasiswa. Gedung-gedung tersebut disupplay oleh satu transformator yang dibantu oleh pihak PT. PLN (Persero) cabang Pekanbaru. Adapun tegangan primer transformator sebesar $20 \mathrm{kV}$ dan tegangan sekunder yang dipakai adalah tegangan tiga phasa 380 volt dan tegangan satu phasa 220 volt.

UNITEX Vol 12 No.2 Juli-Desember 2019

| p-ISSN 2089-3957 | e-ISSN 2580-2585 


\section{Data dan Objek Pembahasan.}

Pada penelitian ini dilakukan pada bulan Juni 2019 dengan melakukan survey lapangan untuk mendapatkan data-data primer serta gambaran umum tentang kelistrikan di Universitas Lancang Kuning. Dari hasil survey penelitian di lapangan diperoleh data pemakaian beban pada masing-masing gedung fakultas dan gedung rektorat.

Tabel 1. Data pemakaian beban di Universitas Lancang Kuning

\begin{tabular}{|c|l|c|c|c|c|}
\hline \multirow{2}{*}{ No Nama Gedung } & \multicolumn{3}{|c|}{ Beban (A) } & \multirow{2}{*}{ Total Beban (A) } \\
\cline { 3 - 5 } & & $\mathbf{R}$ & $\mathbf{S}$ & $\mathbf{T}$ & \\
\hline 1 & Rektorat & 35,6 & 24,5 & 30,5 & 90,6 \\
\hline 2 & Fakultas Ilmu Budaya & 7,2 & 2,6 & 1,6 & 11,4 \\
\hline 3 & Fakultas KIP & 9,3 & 6,9 & 3,2 & 19,4 \\
\hline 4 & Fakultas Ilmu Komputer & 12,6 & 20,8 & 8,4 & 41,8 \\
\hline 5 & Fakultas Pertanian & 23,2 & 16,4 & 12,7 & 52,3 \\
\hline 6 & Fakultas Kehutanan & 1,92 & 1,9 & 0,8 & 4,62 \\
\hline 7 & Fakultas Teknik & 37,6 & 18,7 & 18,2 & 74,5 \\
\hline 8 & Fakultas Ekonomi & 20,5 & 25,8 & 21,4 & 67,7 \\
\hline 9 & Fakultas Ilmu Administrasi & 16,3 & 17,2 & 22.8 & 33,5 \\
10 & Fakultas Hukum & 68,1 & 32,1 & 19,3 & 119,5 \\
\hline 11 & Perpustakaan & 16,9 & 7,3 & 7,8 & 32 \\
\hline 12 & LPPM & 1,8 & 1,2 & 0,6 & 3,6 \\
\hline 13 & Puskom & 6,5 & 3,5 & 5,2 & 15,2 \\
\hline 14 & Asrama Mahasiswa & 2,3 & 1,2 & 0,4 & 3,9 \\
\hline 15 & Mesjid Kampus & 0,4 & 0,9 & 0,5 & 1,8 \\
\hline 16 & Kantin & 6,3 & 5,3 & 2,8 & 14,4 \\
\hline & & $\mathbf{2 6 6 , 5 2}$ & $\mathbf{1 8 6 , 3}$ & $\mathbf{1 3 3 , 4}$ & $\mathbf{5 8 6 , 2 2}$ \\
\hline
\end{tabular}

\section{Data Pemakaian Daya}

Penggunaan kabel yang dipasang pada sistem kelistrikan di Universitas Lancang Kuning ditunjukkan pada Tabel 2.

Tabel 2. Spesifikasi kabel Universitas Lancang Kuning

\begin{tabular}{|l|l|l|l|l|l|l|}
\hline No & \multicolumn{1}{|c|}{ Nama Gedung } & \multicolumn{1}{|c|}{$\begin{array}{c}\text { Jenis } \\
\text { kabel }\end{array}$} & $\begin{array}{c}\text { Luas } \\
\text { Penampang } \\
(\mathrm{mm} 2)\end{array}$ & $\begin{array}{c}\text { Tahanan } \\
(\mathrm{ohm})\end{array}$ & $\begin{array}{c}\text { Impedansi } \\
(\mathrm{R}+\mathrm{jX}) \\
(\mathrm{ohm} / \mathrm{km})\end{array}$ & $\begin{array}{c}\text { Panjang } \\
(\mathrm{m})\end{array}$ \\
\hline 1. & Rektorat & NYFGbY & $4 \mathrm{X} 25$ & 0,76 & 0,09 & 120 \\
\hline 2. & Fak. Ilmu Budaya & NFA2X-T & $3 \mathrm{X} 25+25$ & 1,2 & 0,14 & 100 \\
\hline 3. & Fakultas KIP & NFA2X-T & $3 \mathrm{X} 25+25$ & 1,2 & 0,14 & 100 \\
\hline 4. & $\begin{array}{l}\text { Fak.Ilmu } \\
\text { Komputer }\end{array}$ & NYFGbY & $4 \mathrm{X} 25$ & 0,76 & 0,06 & 100 \\
\hline 5. & Fakultas Pertanian & NFA2X-T & $3 \mathrm{X} 25+25$ & 1,2 & 0,30 & 250 \\
\hline 6. & $\begin{array}{l}\text { Fakultas } \\
\text { Kehutanan }\end{array}$ & NFA2X-T & $3 \mathrm{X} 25+25$ & 1,2 & 0,36 & 300 \\
\hline 8. & Fakultas Teknik & NYFGbY & $4 \mathrm{X} 25$ & 0,76 & 0,27 & 350 \\
\hline 8. & Fakultas Ekonomi & NFA2X-T & $3 \mathrm{X} 25+25$ & 1,2 & 0,50 & 350 \\
\hline 9. & Fak. Ilmu & NFA2X-T & $3 \mathrm{X} 25+25$ & 1,2 & 0,58 & 400 \\
\hline
\end{tabular}




\begin{tabular}{|l|l|l|l|l|l|l|} 
& Administrasi & & & & \\
\hline 10. & Fakultas Hukum & NFA2X-T & $3 \mathrm{X} 25+25$ & 1,2 & 1,20 & 1000 \\
\hline 11. & Perpustakaan & NFA2X-T & $3 \mathrm{X} 25+25$ & 1,2 & 0,36 & 250 \\
\hline 12. & LPPM & NFA2X-T & $3 \mathrm{X} 25+25$ & 1,2 & 0,36 & 250 \\
\hline 13. & Puskom & NFA2X-T & $3 \mathrm{X} 25+25$ & 1,2 & 0,36 & 250 \\
\hline 14. & $\begin{array}{l}\text { Asrama } \\
\text { Mahasiswa }\end{array}$ & NFA2X-T & $3 \times 25+25$ & 1,2 & 1,15 & 800 \\
\hline 15. & Mesjid Kampus & NFA2X-T & 3 X $25+25$ & 1,2 & 0,94 & 650 \\
\hline 16. & Kantin & NFA2X-T & 3 X $25+25$ & 1,2 & 0,36 & 300 \\
\hline
\end{tabular}

\section{Menghitung Jatuh Tegangan}

Berdasarkan data Tabel 1 dapat dilakukan perhitungan drop tegangan diperoleh sebagai berikut:

$$
\begin{aligned}
\Delta V & =I \times Z \\
& =(90,6) \times 0,09 \\
& =8,15 \text { volt }
\end{aligned}
$$

Maka tegangan diperoleh

$$
\begin{aligned}
& =380-8,15 \\
& =371,85 \text { volt }
\end{aligned}
$$

Hasil perhitungan jatuh tegangan untuk gedung selanjutnya ditunjukkan pada Tabel 3 .

Tabel 3. Hasil perhitungan jatuh tegangan dan tegangan terendah di Universitas Lancang Kuning

\begin{tabular}{|c|l|c|r|}
\hline \multirow{2}{*}{ No } & \multicolumn{1}{|c|}{ Nama Gedung } & \multicolumn{2}{c|}{ Tegangan (volt) } \\
\cline { 3 - 4 } & & $\begin{array}{c}\text { Tatuh Tegangan } \\
(\mathbf{\Delta V})\end{array}$ & $\begin{array}{c}\text { Tegangan } \\
\text { Terendah } \\
(\mathbf{V s})\end{array}$ \\
\hline 1. & Rektorat & 8,26 & 371,74 \\
\hline 2. & Fakultas Ilmu Budaya & 1,64 & 378,36 \\
\hline 3. & Fakultas KIP & 2,79 & 377,21 \\
\hline 4. & Fakultas Ilmu Komputer & 2,41 & 377,59 \\
\hline 5. & Fakultas Pertanian & 15,69 & 364,31 \\
\hline 6. & Fakultas Kehutanan & 1,66 & 378,34 \\
\hline 7. & Fakultas Teknik & 19,82 & $\mathbf{3 6 0 , 1 8}$ \\
\hline 8. & Fakultas Ekonomi & 34,12 & $\mathbf{3 4 5 , 8 8}$ \\
\hline 9. & Fakultas Ilmu Administrasi & 19,30 & $\mathbf{3 6 0 , 7 0}$ \\
\hline 10. & Fakultas Hukum & 143,40 & $\mathbf{2 3 6 , 6 0}$ \\
\hline 11. & Perpustakaan & 11,52 & 368,48 \\
\hline 12. & LPPM & 1,30 & 378,70 \\
\hline 13. & Puskom & 5,47 & 374,53 \\
\hline 14. & Asrama Mahasiswa & 4,49 & 375,51 \\
\hline 15. & Mesjid Kampus & 1,68 & 378,32 \\
\hline 16. & Kantin & 5,18 & 374,82 \\
\hline & Jumlah Total & $\mathbf{2 7 8 , 7 5}$ & \\
\hline
\end{tabular}




\section{Menghitung Rugi-Rugi Daya}

Berdasarkan Tabel 1 dapat dihitung rugi-rugi daya pada gedung rektorat:

$$
\begin{aligned}
\Delta \mathrm{P} & =\mathrm{I}^{2} \times \mathrm{R}(\text { Watt }) \\
& =(90,6)^{2} \times 0,76 \\
& =6238 \mathrm{watt} \\
& =6,238 \mathrm{kWatt}
\end{aligned}
$$

Dari hasil perhitungan rugi-rugi daya untuk gedung selanjutnya dapat dilihat pada Tabel 5

Tabel 5. Rugi daya Universitas Lancang Kuning

\begin{tabular}{|c|l|c|}
\hline No & \multicolumn{1}{|c|}{ Nama Gedung } & Rugi Daya $(\Delta \mathbf{P})$ (watt) \\
\hline 1. & Rektorat & 6238 \\
\hline 2. & Fakultas Ilmu Budaya & 156 \\
\hline 3. & Fakultas KIP & 452 \\
\hline 4. & Fakultas Ilmu Komputer & 1328 \\
\hline 5. & Fakultas Pertanian & 3282 \\
\hline 6. & Fakultas Kehutanan & 26 \\
\hline 7. & Fakultas Teknik & 4218 \\
\hline 8. & Fakultas Ekonomi & 5500 \\
\hline 9. & Fakultas Ilmu Administrasi & 1347 \\
\hline 10. & Fakultas Hukum & 17136 \\
\hline 11. & Perpustakaan & 1229 \\
\hline 12. & LPPM & 16 \\
\hline 13. & Puskom & 277 \\
\hline 14. & Asrama Mahasiswa & 18 \\
\hline 15. & Mesjid Kampus & 4 \\
\hline 16. & Kantin & $\mathbf{4 1 4 7 6}$ \\
\hline \multicolumn{2}{|c|}{ Total } & \\
\hline
\end{tabular}

Berdasarkan hasil perhitungan rugi-rugi daya total sebesar 41476 watt atau 41,476 $\mathrm{kW}$ dan tegangan terendah, jatuh tegangan dapat dilihat pada tabel 6 .

Tabel 6. Hasil perhitungan

\begin{tabular}{|c|l|c|c|c|}
\hline \multirow{2}{*}{ No } & \multicolumn{1}{|c|}{ Nama Gedung } & \multicolumn{3}{|c|}{ Tegangan (volt) } \\
\cline { 3 - 5 } & \multicolumn{1}{|c|}{} & $\begin{array}{c}\text { Jatuh } \\
\text { Tegangan } \\
(\Delta \mathbf{V})\end{array}$ & $\begin{array}{c}\text { Tegangan } \\
\text { Terendah } \\
(\text { Vs) }\end{array}$ & $\begin{array}{c}\text { Rugi Daya } \\
(\Delta \mathbf{P})\end{array}$ \\
\hline 1. & Fakultas Teknik & 19,82 & 360,18 & 4218 \\
\hline 2. & Fakultas Ekonomi & 34,12 & 345,88 & 5500 \\
\hline 3. & Fakultas Ilmu Administrasi & 19,30 & 360,70 & 1347 \\
\hline 4. & Fakultas Hukum & 143,40 & 236,60 & 17136 \\
\hline
\end{tabular}


Pemakaian beban dilingkungan Universitas Lancang Kuning terjadi ketidak seimbangan beban pada masing-masing phasa $\mathrm{R}$ sebesar 266,52 Amper, phasa $\mathrm{S}$ sebesar 186,3 Amper dan phasa T sebesar 133, 4 Amper, sehingga jumlah total pemakaian beban sebesar 586,22 Amper.

Pemasangan energi listrik di gedung FKIP dipakai melebihi pemakaian energi listrik yang lebih besar khususnya di laboratorium. Maka perhitungan kapasitas daya untuk penambahan gedung Fakultas Keguruan dan Ilmu Pendidikan adalah :

$$
\begin{aligned}
S & =\frac{P}{C o s \varphi} \\
& =\frac{44629 \text { watt }}{0,8} \\
& =55786 \mathrm{VA} \\
& =55,786 \mathrm{kVA} \\
& \approx 60 \mathrm{kVA}
\end{aligned}
$$

Jadi kebutuhan kapasitas daya untuk gedung Fakultas Keguruan dan Ilmu Pendidikan sebesar $60 \mathrm{kVA}$.

\section{Simpulan}

1. Tegangan terima terendah di lingkungan Universitas Lancang Kuning terdapat pada fakultas teknik sebesar 360,18 volt, fakultas Ekonomi sebesar 345,88 volt, fakultas Ilmu Administrasi sebesar 360,70 volt dan fakultas Hukum sebesar 236,60 volt.

2. Jatuh tegangan terjadi di lingkungan Universitas Lancang Kuning terdapat di fakultas Teknik sebesar 19,82 volt, fakultas Ekonomi sebesar 34,12 volt, fakultas Ilmu Administrasi sebesar 19,30 volt dan fakultas Hukum sebesar 143,40 volt.

3. Jumlah rugi-rugi daya total di lingkungan Universitas Lancang Kuning sebesar 41,476 kWatt.

4. Untuk penambahan gedung Fakultas Keguruan dan Ilmu Pendidikan dibutuhkan kapasitas daya sebesar $60 \mathrm{kVA}$ untuk memenuhi pemakaian energi di gedung FKIP yang baru.

5. Pemakaian beban dilingkungan Universitas Lancang Kuning terjadi ketidak seimbangan beban pada masing-masing phasa $\mathrm{R}$ sebesar 266,52 Amper, phasa S sebesar 186,3 Amper dan phasa T sebesar 133, 4 Amper, sehingga jumlah total pemakaian beban sebesar 586,22 Amper.

UNITEX Vol 12 No.2 Juli-Desember 2019 p-ISSN 2089-3957 | e-ISSN 2580-2585 


\section{Daftar Pustaka}

Belén G., Juan C.B., \& Ángel M.A. Transformer Tank Vibration Modeling as a Method of Detecting Winding Deformations. IEEE Transactions On Power Delivery, 21(1).

Zuhal. (2000). Dasar Teknik Tenaga Listrik Dan Elektronika Daya. PT Gramedia Pustaka Utama: Jakarta.

Abdul, K. Transformator. PT. Elex Komputindo Kelompok Gramedia: Jakarta.

Berahim, H. Pengantar Teknik Tenaga Listrik. Andi Offset: Yogyakarta.

Soebagio. (2012). Transformator. ITS Press. Surabaya.

Julius, S.S. (2012). Pengaruh Ketidakseimbangan Beban terhadap Netral dan Losses pada Trafo. Jurnal Teknik.

Kshira T., Muthanna, Abhinanda Sarkar, Kaushik D., \& Kurt W. Transformer Insulation Life Assessment. (2006). IEEE Transactions On Power Delivery, 21(1). 